\title{
Genome-wide identification, characteristics and expression of the prolamin genes in Thinopyrum elongatum
}

\author{
Wenyang $\mathrm{Ge}^{\dagger}, \mathrm{Yu} \mathrm{Gao}{ }^{\dagger}$, Shoushen Xu, Xin Ma, Hongwei Wang, Lingrang Kong and Silong Sun *
}

\begin{abstract}
Background: Prolamins, unique to Gramineae (grasses), play a key role in the human diet. Thinopyrum elongatum (syn. Agropyron elongatum or Lophopyrum elongatum), a grass of the Triticeae family with a diploid $\mathrm{E}$ genome $(2 \mathrm{n}=$ $2 x=14$ ), is genetically well-characterized, but little is known about its prolamin genes and the relationships with homologous loci in the Triticeae species.

Results: In this study, a total of 19 a-gliadin, 9 -gliadin, $19 \omega$-gliadin, 2 high-molecular-weight glutenin subunit (HMW-GS), and 5 low-molecular-weight glutenin subunit (LMW-GS) genes were identified in the Th. elongatum genome. Micro-synteny and phylogenetic analysis revealed dynamic changes of prolamin gene regions and genetic affinities among Th. elongatum, Triticum aestivum, T. urartu and Aegilops tauschii. The Th. elongatum genome, like the B subgenome of T. aestivum, only contained celiac disease epitope DQ8-glia-a1/DQ8.5-glia-a1, which provided a theoretical basis for the low gluten toxicity wheat breeding. The transcriptome data of Th. elongatum exhibited differential expression in quantity and pattern in the same subfamily or different subfamilies. Dough rheological properties of T. aestivum-Th. elongatum disomic substitution (DS) line 1E(1D) showed higher peak height values than that of their parents, and DS6E(6D) exhibited fewer a-gliadins, which indicates the potential usage for wheat quality breeding.
\end{abstract}

Conclusions: Overall, this study provided a comprehensive overview of the prolamin gene family in Th. elongatum, and suggested a promising use of this species in the generation of improved wheat breeds intended for the human diet.

Keywords: Thinopyrum elongatum, Prolamins, Expression, Evolution, Celiac disease

\section{Background}

Prolamins (glutenins and gliadins), comprising $80 \%$ of wheat endosperm protein, are the main component of glutens [1]. High- and low-molecular-weight glutenin subunits (HMW-GSs and LMW-GSs) form polymeric proteins by interchain disulfide bonds, imparting the elasticity of dough. Gliadins, divided into $\alpha_{-}, \beta-, \gamma_{-}^{-}$, and $\omega$-gliadins, are monomeric proteins of $30-78 \mathrm{kDa}$ that

\footnotetext{
* Correspondence: sunsl@sdau.edu.cn

†'Wenyang Ge and Yu Gao contributed equally to this work. State Key Laboratory of Crop Biology, College of Agronomy, Shandong Agricultural University, Tai'an 271018, China
}

determine the ductility and viscosity of dough [2-5]. These unique properties determine the quality of wheat flour in various technological processes and enable the manufacture of a wide range of products such as bread, pasta, noodles, cakes, and pastries [6, 7]. Prolamin genes were reported to be closely linked and mainly located on a few chromosomes in common wheat [8]. The HMWGS genes are encoded by the Glu-1 loci on the long arm of the first homologous group [9]. The $\gamma$-gliadin and $\omega$ gliadin genes are encoded by the Gli-1 loci closely linked to the Glu-3 loci encoding LMW-GS genes on the short arm of the same chromosome, on which HMW-GS

(c) The Author(s). 2021 Open Access This article is licensed under a Creative Commons Attribution 4.0 International License, which permits use, sharing, adaptation, distribution and reproduction in any medium or format, as long as you give appropriate credit to the original author(s) and the source, provide a link to the Creative Commons licence, and indicate if changes were made. The images or other third party material in this article are included in the article's Creative Commons licence, unless indicated otherwise in a credit line to the material. If material is not included in the article's Creative Commons licence and your intended use is not permitted by statutory regulation or exceeds the permitted use, you will need to obtain permission directly from the copyright holder. To view a copy of this licence, visit http://creativecommons.org/licenses/by/4.0/ The Creative Commons Public Domain Dedication waiver (http://creativecommons.org/publicdomain/zero/1.0/) applies to the data made available in this article, unless otherwise stated in a credit line to the data. 
genes are located [10]. The $\alpha$-gliadin genes are encoded by the Gli-2 loci on the short arm of the sixth homologous group [11].

Prolamin genes belong to a large family. Comprehensive understanding of these genes is challenging, but essential for improving the end-use quality of wheat flour [7]. Generally, T. urartu (AA, $2 \mathrm{n}=2 \mathrm{x}=14$ ) and Ae. Tauschii (DD, $2 \mathrm{n}=2 \mathrm{x}=14$ ) are regarded as donors of the A and D genomes of common wheat [12]. Th. elongatum, closely related to wheat, has excellent performance in biotic and abiotic stress resistance [13]. At present, genome data of these Triticeae species have been published, but the relationship among their prolamin genes has not been well described, including gene features and molecular characteristics [13-16]. High pseudogene rate was associated with gliadin families and this was estimated to be $87 \%$ of 230 distinct $\alpha$-gliadin gene sequences in several diploid wheat species [1]. Hence, it is necessary to understand the expression profile of these genes to clarify the mechanism of gene activation. However, current research is still insufficient, especially regarding species other than common wheat [17].

Gene clusters of a gene family are often prone to genetic variations in copy number, sequence polymorphism, and expression [18]. Comparisons of these homologous regions between different genomes of related species will provide insights into gene differentiation, as well as local rearrangements [19]. For example, a comparison of the Gli-2 loci between T. dicoccoides Korn and T. aestivum cv. Chinese Spring (CS) showed a large sequence difference between the two A subgenomes and a conservative region between the two B subgenomes [20]. To date, a detailed analysis of other genomes (except for the A, B, and $\mathrm{D}$ genomes) on the interval of these loci has not been reported.

Gluten is the most important source of proteins in common wheat for human beings. Unfortunately, prolamins of gluten are also responsible for certain intolerances, among which celiac disease (CD) is one of the most common wheat-related disorders [21]. $\mathrm{CD}$ is a chronic intestinal immune-mediated bowel disease, which occurs in genetically susceptible people and is caused by the intake of gluten [22]. $\alpha$-gliadins are the main substance causing CD [18]. A breeding effort had been proposed to develop wheat with reduced immunoreactive epitopes while retaining baking functions [23]. Prolamin genes from wild relatives of wheat were reported to have low gluten toxicity and could be used to improve wheat quality by distant hybridization [24].

In this study, prolamin genes were obtained and comparative analysis were carried out between Th. elongatum and three related species (T. aestivum, T. urartu, and Ae. tauschii) in terms of gene numbers, molecular characteristics, micro-synteny, phylogenetic relationship, $\mathrm{CD}$ epitope content and dynamic expression pattern. Mixogram tests of disomic substitution (DS) line 1E(1D) was also performed. The results presented will provide helpful information of prolamin genes in Triticeae and future application in wheat breeding.

\section{Results}

Identification of the prolamin genes in Th. Elongatum and error correction in the related species

A total of $19 \alpha$-gliadin, $9 \gamma$-gliadin, $19 \omega$-gliadin, 2 HMW-GS, and 5 LMW-GS genes were identified in the $T h$. elongatum genome while no $\delta$-gliadin genes were detected (Additional file 1: Table S1). Prolamin genes in the related species were also collected and reannotated. In addition, some annotation errors were found in related species. For example, there were no sequences for AET6Gv20125500.1 and AET6Gv20126100.1 in the existing CDS and protein files of Ae. tauschii. By checking their positions provided in that study, we found an incorrect coordinate layout (Additional file 1: Table S2) [15]. Several $\delta$-gliadins were also identified in T. aestivum genome (Additional file 1: Table S4). All prolamin genes found in this study were manually checked and corrected according to their structure information (Additional file 1: Table S3 and Table S4) [8, 25-28].

\section{Characteristics and sequence analysis of the prolamin gene family}

All prolamin genes of four species were first named based on abbreviations of species names and chromosomal locations. Then, the isoelectric point (pI), molecular weight $(\mathrm{MW})$ and other characteristics of putative functional prolamin genes were calculated (Additional file 1: Table S4). No obvious differences were found between Th. elongatum and other three species except for Tel_LMW_glutenin_1E_1, a special prolamin gene that has the highest MW and the longest protein sequence (Additional file 1: Table S4).

The prolamin gene numbers showed variable patterns among different ploidy species (Fig. 1a). Only HMW-GS gene subfamily, carrying one $x$-type and one y-type in each diploid genome, follow a conservative pattern in the process of evolution [7]. In contrast, no specific pattern was observed among gliadin subfamilies across the species. What is particularly noticeable is that Th. elongatum had the highest numbers in three gliadin subfamilies of the three diploid species, and the number of $\omega$-gliadin genes of Th. elongatum was about 3-5 times than that of the other two diploid species. A common feature of gliadin genes in the four species was that the numbers of $\alpha$-gliadin genes were the largest, followed by $\omega$-gliadin genes, and finally $\gamma$-gliadin genes. 


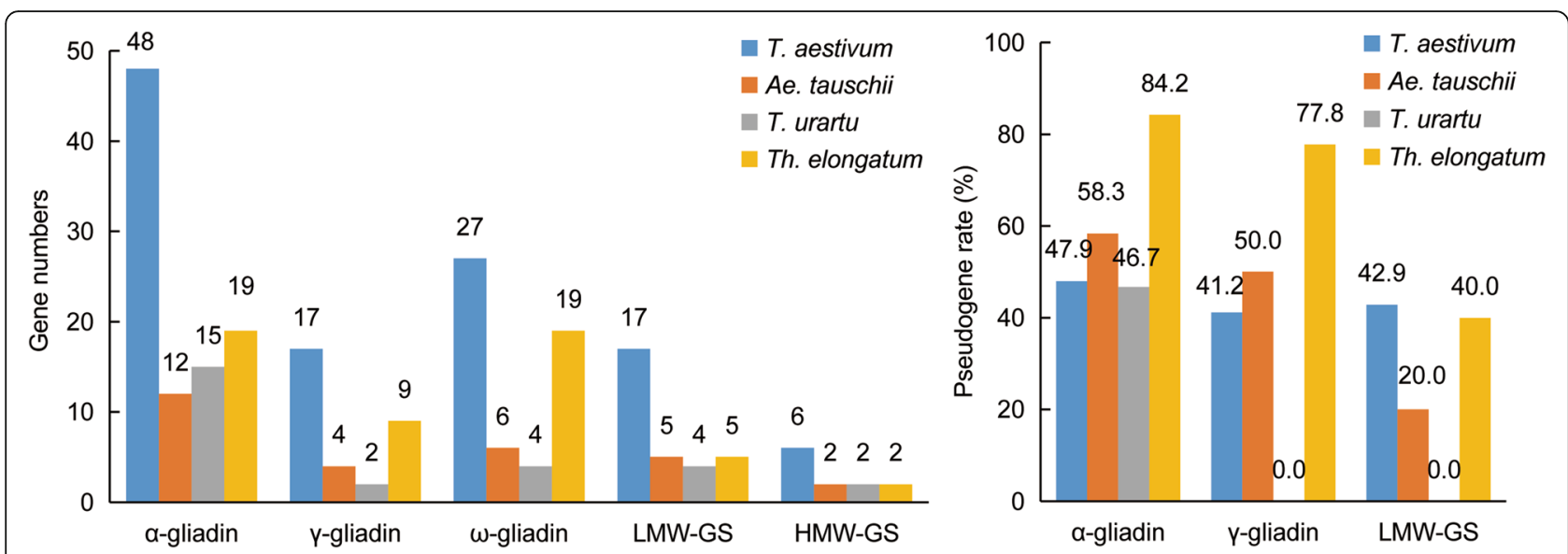

Fig. 1 Characteristic comparisons of prolamin genes. A The number of each prolamin gene subfamily among Th. elongatum, T. aestivum, T. urartu and Ae. tauschii. B Pseudogene rates of a-gliadin, $\gamma$-gliadin and LMW-GS gene families among four selected species

The pseudogene rates of each prolamin subfamilies were calculated according to the pseudogene number based on the inference from coding sequences to protein sequences (Additional file 1: Table S3). Th. elongatum had the highest pseudogene rates in $\alpha$-gliadin (84.2\%) and $\gamma$-gliadin gene families $(77.8 \%)$, while no pseudogenes were found in $\gamma$-gliadin and LMW-glutenin gene families in T. urartu (Fig. 1b).

\section{Chromosomal location and duplication of prolamin genes}

Consistent with previous studies, the $\gamma$-gliadin, $\omega$-gliadin and LMW-GS genes were distributed on the short arm, and the HMW-GS genes were located on the long arm of the first homologous group $[10,29,30]$. Most $\alpha-$ gliadins were mainly distributed on the sixth homologous group (Fig. 2) [11]. It is interesting to note that a new $\alpha$-gliadin cluster with four pseudogenes was detected on the short arm of chromosome 7E $(109,202,365-109,312,140 \mathrm{bp})$. Both tandem duplication and segmental duplication are associated with gene production. The proportions of tandem duplication genes of $\alpha_{-}^{-}, \gamma^{-}, \omega$-gliadins and LMW-GSs in Th. elongatum were $73.7,88.9,68.4$ and 50\%, which supports the hypothesis that the major expansion of prolamin genes was through tandem duplication.

To better understand the evolutionary mechanism of $\gamma$-gliadin, $\omega$-gliadin and LMW-GS gene subfamilies, an interval covering the first to the last prolamin gene on the short arm of the first homologous group was used for micro-synteny analysis among the four genomes (Fig. 3). The results showed that all these regions were located in collinear blocks with an inversion occurred between Glu-3 and Gli-1 loci on chromosome 1D of common wheat and one isolated $\omega$-gliadin gene existed in Th. elongatum, A and B subgenomes of common wheat but lost in T. urartu, Ae. Tauschill and the D subgenome. Micro-synteny analysis of $\alpha$-gliadins in the four studied species exhibited multiple duplicates in the loci expect for D genomes (Additional file 2). Although gene collinearity appears to be retained, four of six genes including the two paralogous HMW-GS genes were reversed in the homologous region of the T. urartu genome (Additional file 2) [31]. Changes in these gene loci between related species provided evidences for the dynamic evolution of the prolamin gene family.

\section{Evolutionary analysis of prolamin subfamilies}

Phylogenetic trees were constructed for each prolamin gene subfamilies to investigate the internal evolutionary relationship within Triticeae species. GQ139526.1 (Psathyrostachys huashanica), X13508.1 (Hordeum vulgare), HQ293220.1 (Dasypyrum villosum) and FJ481574.2 (Eremopyrum triticeum) were selected as outgroups, respectively.

All $66 \alpha$-gliadin genes were divided into 8 clades and genes from the same genome were generally clustered together (Fig. 4). It is interesting to note that 4 genes located on the 7E chromosome of Th. elongatum formed a separate clade (clade 8) with a high bootstrap value and had a closer genetic distance with the outgroup species, which indicates that these genes on chromosome $7 \mathrm{E}$ evolved earlier than those on chromosome $6 \mathrm{E}$ and formed as a result of different evolutionary trajectories in early stages. In HMW-GS gene subfamily, all 12 genes were well divided into 2 clades, representing y-type HMW-GSs (clade 1) and x-type HMW-GSs (clade 2) (Additional file 3) [14]. The topological structure of $y$ type HMW-GSs had some differences with $\mathrm{x}$-type HMW-GSs, which might be related to the sequence variation of the C-terminal region of y-type HMW-GSs. The LMW-GS, $\gamma$-gliadin and $\omega$-gliadin gene subfamilies showed similar phylogenetic relationship as $\alpha$-gliadin 


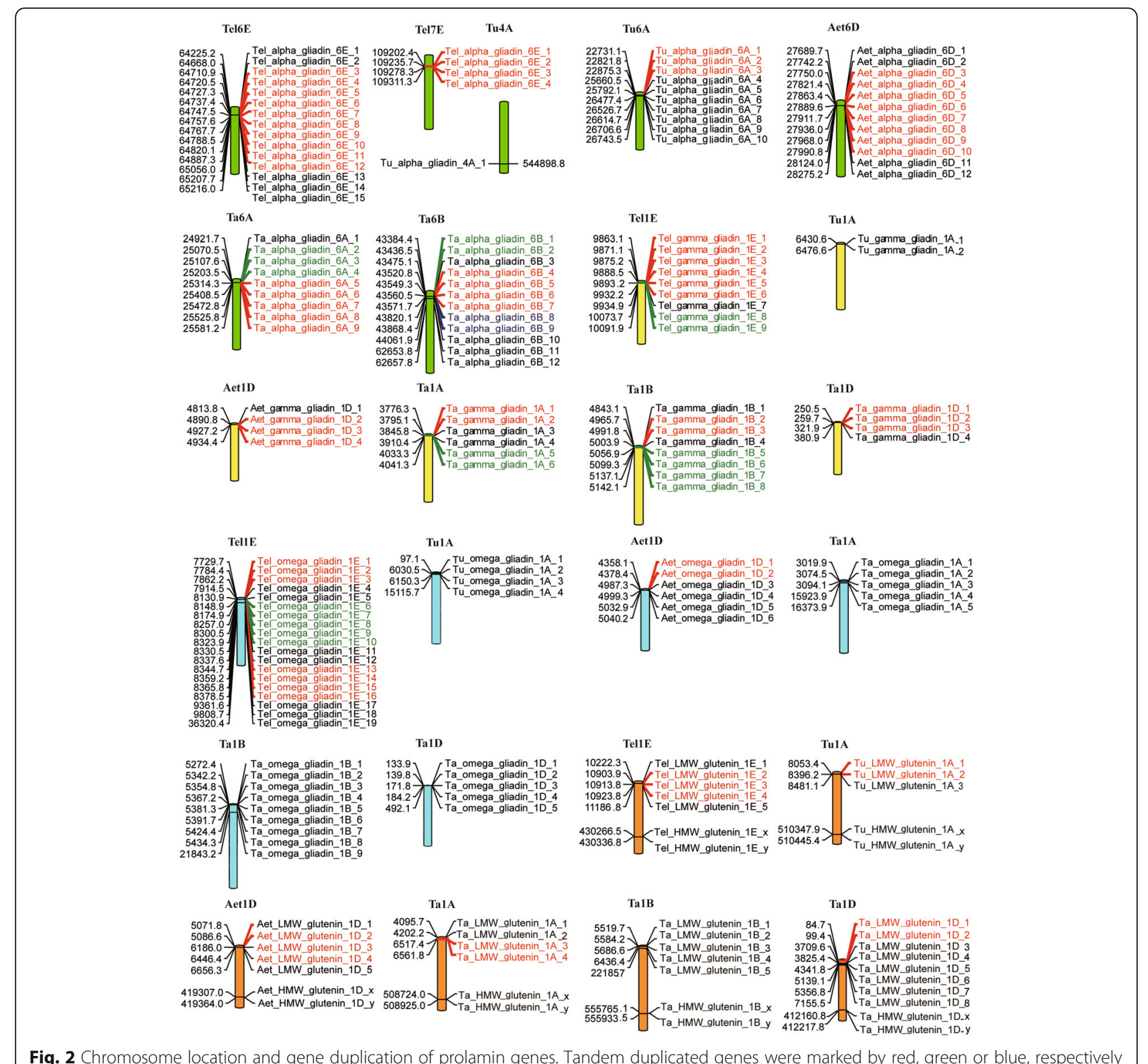

Fig. 2 Chromosome location and gene duplication of prolamin genes. Tandem duplicated genes were marked by red, green or blue, respectively

and HMW-GS genes (Additional file 3 and Additional file 4).

\section{Distribution of $C D$ epitopes in a-gliadins genes}

The most influential $\mathrm{T}$ cell epitopes in $\mathrm{CD}$ patients are PFPQPQLPY (DQ2.5-glia- $\alpha 1 \mathrm{a})$, PYPQPQLPY (DQ2.5glia- $\alpha 1 b), P Q P Q L P Y P Q$ (DQ2.5-glia- $\alpha 2$ ), FRPQQQPY PQ (DQ2.5-glia- $\alpha$ 3), and QGSFQPSQQ (DQ8-glia- $\alpha 1 /$ DQ8.5-glia- $\alpha 1$ ), as well as the most toxic 33-mer peptide (LQLQPFPQPQLPYPQPQLPYPQPQLPYPQPQPF) [32, 33]. About 93.3\% $\alpha$-gliadin genes contained DQ2.5-glia$\alpha 1$ a or DQ2.5-glia- $\alpha 3$ in the A genomes, but only $28.6 \%$ contained only one type epitope (DQ8-glia- $\alpha 1 / D Q 8.5-$ glia- $\alpha 1$ ) in the $B$ genomes (Additional file 1: Table S5).
The epitope types in the $\mathrm{D}$ genome were the most abundant and all six types were identified. The $\mathrm{E}$ genome, like the $\mathrm{B}$ genome, also only contained one type epitope, DQ8-glia- $\alpha 1 / D Q 8.5$-glia- $\alpha 1$. 33-mer peptide was only detected in the D genome of common wheat, which was consisted with previous report [1]. DQ2.5-glia- $\alpha 1 \mathrm{~b}$ and DQ2.5-glia- $\alpha 2$ were also only found in the D genome and often existed in the form of multiple peptides, especially DQ2.5-glia- $\alpha 2$, and in contrast the other small peptides existed in the form of single peptides.

\section{Expression pattern of prolamin genes in Th. Elongatum}

The expression of prolamin genes in Th. elongatum were investigated with transcriptome data collected at six 


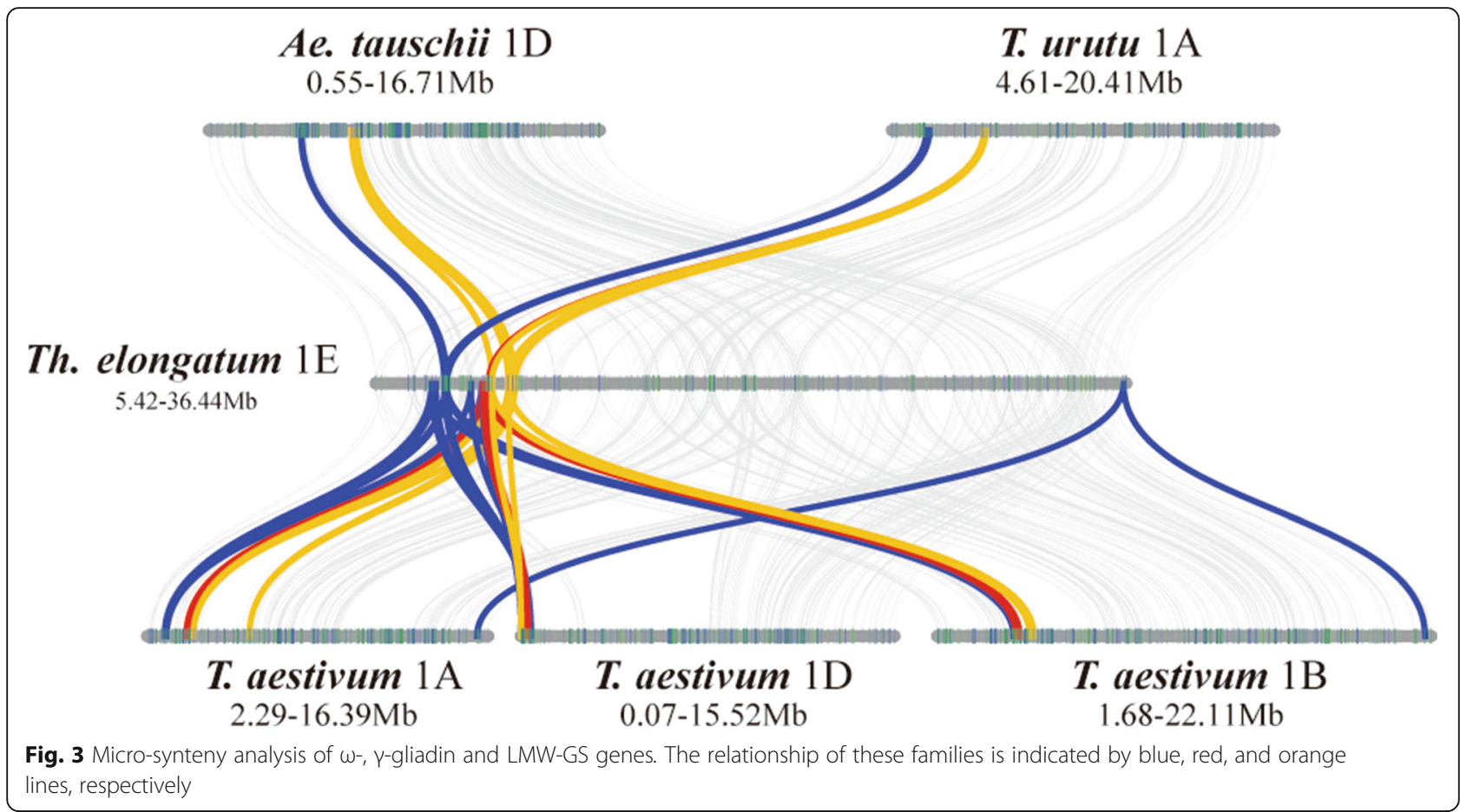

development stages (Fig. 5 and Additional file 1: Table S6). Genes with predicted putative functions (Marked with asterisk) were tended to have a higher TPM value than pseudogenes, which indicted high accurate prediction of our study. Comparative analysis revealed that the expression pattern of prolamin genes in Th. elongatum were different in the same subfamily, which was one of the factors influencing grain prolamin content. For example, the expression of Tel_gamma_gliadin_1E_8 was about 5-6 times than that of Tel_gamma_gliadin_1E_2. Slight differences in gene expression were found in the $\alpha$-gliadin, LMW-GS and HMW-GS gene subfamilies. In addition, different prolamin gene subfamilies had their own specific expression patterns. In $\alpha$-gliadin and LMW-GS gene subfamilies, the expression level of these genes in the half-grain stage was higher than that in the grain stage, which indicated that expression of these genes increased at first and then decreased [27]. However, expression of $\gamma$-gliadin genes was increasing and we speculate that they will decline rapidly or slowly in the future due to reduced gene activity with the maturity of grains. In the HMW-GS gene subfamily, the expression of $\mathrm{x}$-type HMW-GS genes was different from that of $y$-type. The expression of Tel_hmw_glutenin_1 $E_{-} \mathrm{x}$ in the half-grain stage was higher than that in the grain stage, while the expression of Tel_hmw_glutenin_1E_y increased slightly from the half-grain to the grain stage.

In addition, 59 starch synthesis related genes were found in Th. elongatum by homologous sequences search of previous reported wheat starch metabolic related genes [34]. Expression of these genes at six grain development stages was investigated and profiled (Additional file 5). Of the 4 expressed aldolases (ALDs), obvious pattern was observed that these genes were expressed before ovary expansion, whose function were produce fructose-6-P through the gluconeogenic pathway and then convert to glucose-6-P by PGIs to maintain carbon flux toward starch formation [34]. AGPL1 and AGPS1 were expressed at the early stage of grain development, which was consisted with previous study [35]. GBSSI, a granule-bound starch synthase enzyme, expressed at the beginning of grain development, then reached the peak at the half grain stage, suggesting an important role in the seed development [36]. Nevertheless, a large number of starch synthesis-related genes were not expressed in Th. elongatum, which may give a explanation why its seeds is much smaller than common wheat. Overall, although some starch metabolic related genes follow similar express pattern as gluten genes in Th. elongatum, but most of them showed different patterns, how genes in protein and starch metabolic pathways are coordinated for the gliadins and glutenins accumulation need more research.

\section{Electrophoretic maps and kneading quality performance of disomic substitution lines}

In order to investigate the potential usage of $T h$. elongatum prolamin family in wheat high quality breeding, we have speculated the protein expression and processing quality of $T$. aestivum-Th. elongatum 


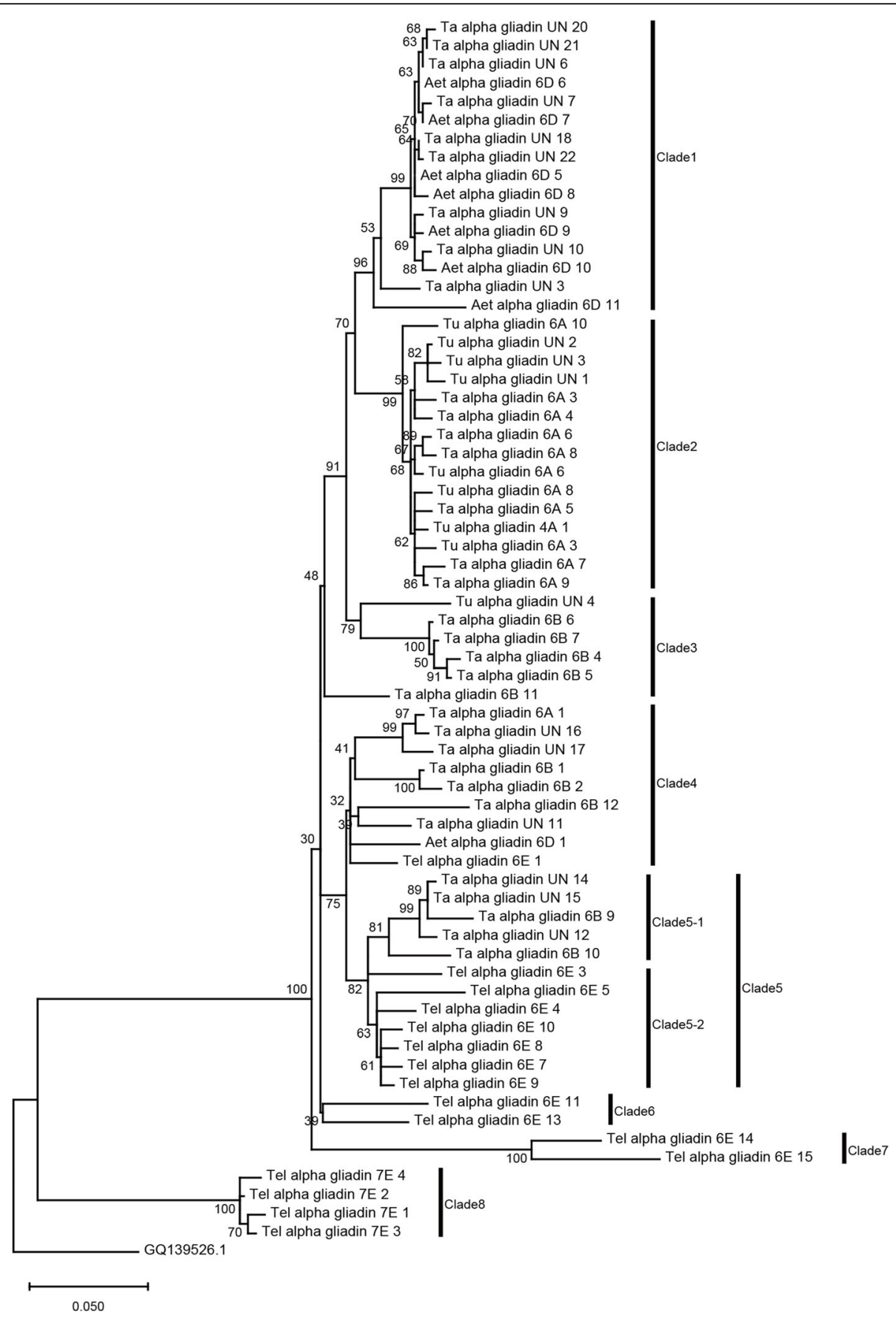

Fig. 4 Phylogenetic tree of a-gliadin genes. The phylogenetic tree was constructed by MEGA X with the maximum likelihood (ML) method and 1000 bootstrap replications. GQ139528.1 was set as outgroup. Different clades are marked with vertical bars and the genes of different species can be judged by their names

disomic substitution lines. Considering the distribution pattern of prolamin genes on chromosomes, the substitution lines of DS1E(1D) and DS6E(6D) were mainly studied, which have been identified by genetic markers and cytological approaches (Additional file 6) [37]. The results of A-PAGE electrophoretic map showed that most $\alpha$-gliadins disappeared in the substitution line DS6E(6D) (Fig. 6a), and the two visible bands for $\beta$-gliadins became weakened. This result is consistent with the fact that less $\alpha$-gliadins were expressed in Th. elongatum (Fig. 5), indicating its potential application for quality breeding to reduce $\mathrm{CD}$ causal epitopes. Interestingly, we found one $\omega$ gliadin band in wheat became silent in this 


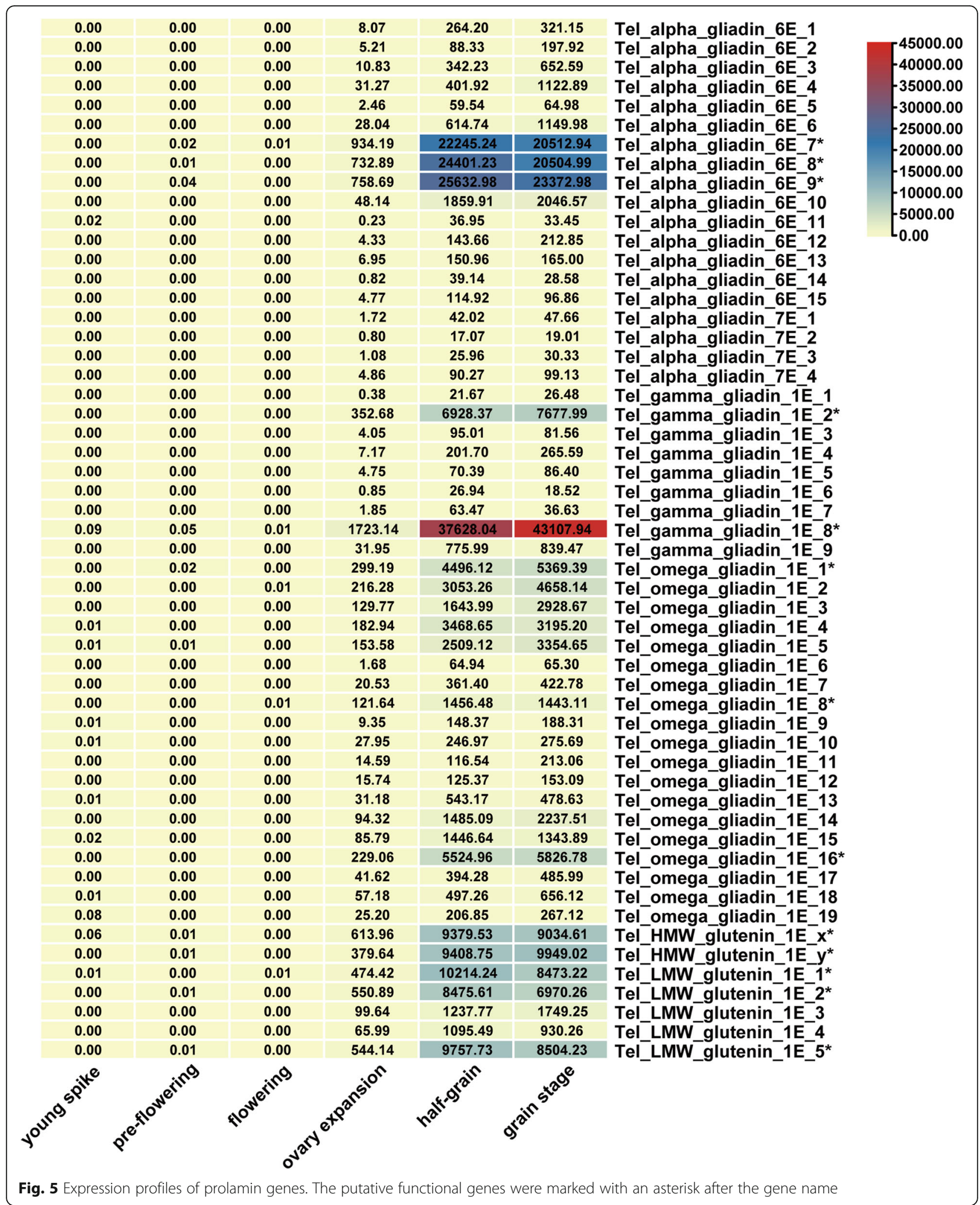

substitution line, which may due to gene silencing during the process of chromosome engineering (Fig. 6a). Even a $\alpha$-gliadin gene cluster have uniquely evolved on the chromosome 7E (Fig. 2), we found no significant difference in the A-PAGE map of DS7E(7D) compared with the control CS 


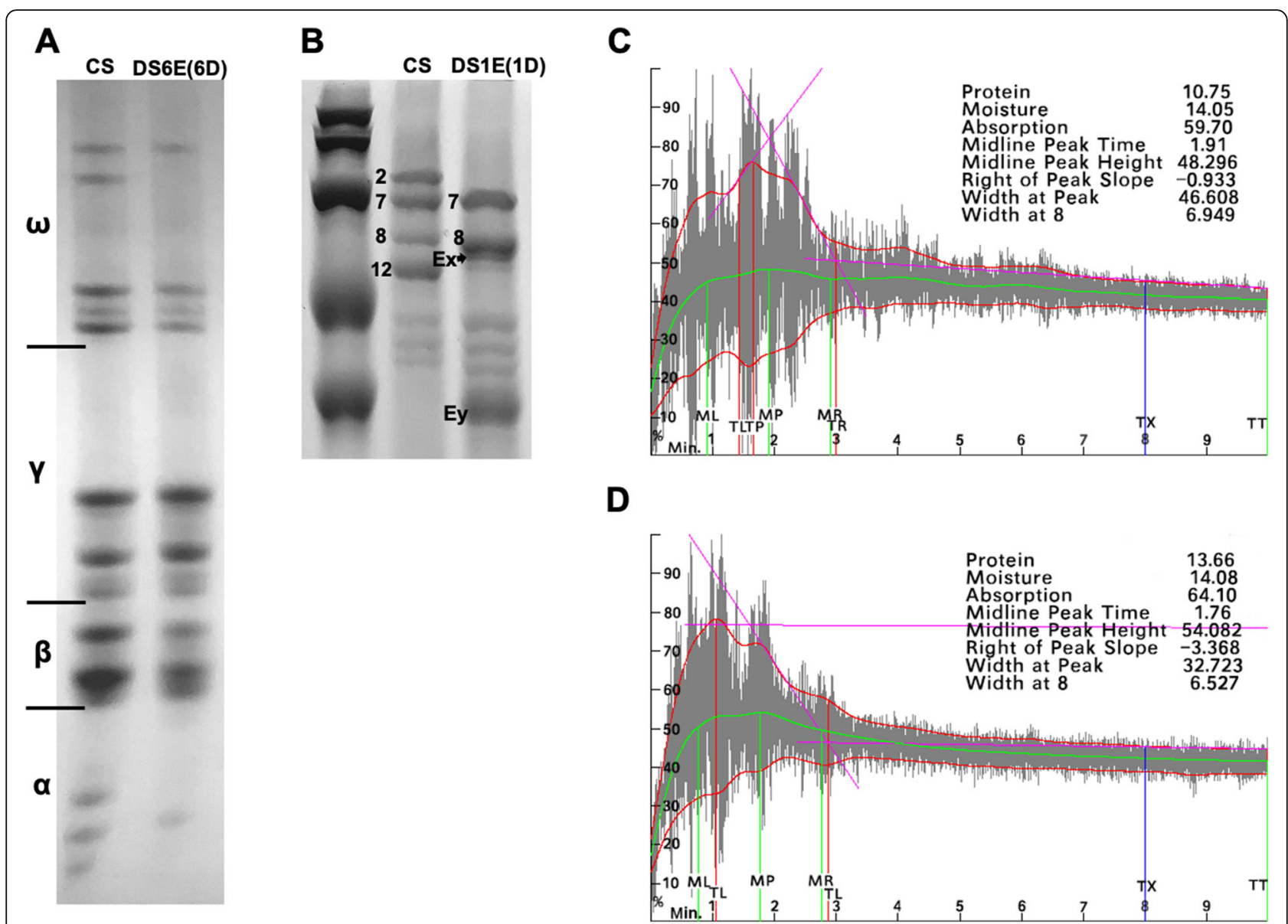

Fig. 6 Electrophoretic map and rheological properties. A A-PAGE electrophoretic patterns of gliadins of CS and DS6E(6D). B 15\% SDS-PAGE electrophoretic patterns of glutenins from CS, DS1E(1D). C-D Rheological properties of CS, DS1E(1D) respectively

(Additional file 7), which was consistent with the transcriptome results that no genes in this cluster were abundantly expressed (Fig. 5).

HWM-GS accounts for $16 \%$ percent of the total wheat gluten protein, but the quality of wheat or gluten quality has a decisive role [38]. Consist with previous reports, CS contained the HMW-GSs of $7+8$ subunits (from B subgenome), and $2+12$ subunits (from D subgenome), named as Glu-B1 and Glu-D1, respectively (Fig. 6b). In the substitution line of DS1E(1D), $2+12$ subunites of Glu-D1 loci were proposed to be substituted by the HWM-GS from E genome, both Ex and Ey subunits were detected in DS1E(1D) (Fig. 6b). Next, kneading parameters were speculated to check the kneading performance of DS1E(1D). The protein content of DS1E(1D) was 3\% higher than that of CS (Fig. 6c and d). There was no significant difference in width at $8 \mathrm{~min}$ between CS and DS1E(1D), but the peak height of DS1E(1D) increased, indicating that the introduction of $1 \mathrm{E}$ chromosome enhanced the kneading resistance of dough (Fig. 6c and d). This is consistent with previous result that the HMW-GSs of E genome may be novel genetic resource for wheat dough quality improvement [28], and the short segment translocation lines can be further created to verify its breeding value.

\section{Discussion}

Prolamin gene families play important roles in flour viscoelasticity, nutritional quality, and $\mathrm{CD}$ epitope content [14-16, 39]. Currently, knowledge is still limited about prolamin genes in Th. elongatum, a well-known species for wheat distant breeding. In this study, we identified $19 \alpha$-gliadins, $9 \gamma$-gliadins, $19 \omega$-gliadins, 2 HMW-GSs, and 5 LMW-GSs in the Th. elongatum genome. Comparison of prolamin genes among four Triticeae species revealed dynamic changes regarding to gene numbers and pseudogene rates, which indicated the complexity and variable of this gene family.

Detailed synteny analysis showed that although the order of $\omega$-gliadin, $\gamma$-gliadin and LMW-GS genes on the first homologous group was maintained among the four studied species, local rearrangement and copy number variation were observed in this interval, revealing a dynamic change in this region (Fig. 3). Similar results were 
also found in $\alpha$-gliadins and HMW-GS subfamilies. Further classification of duplication genes showed that each gene subfamilies was largely composed with tandem duplications $(73.7 \%$ for $\alpha$-gliadins, $88.9 \%$ for $\gamma$-gliadins, $68.4 \%$ for $\omega$-gliadin and $50 \%$ for LMW-GSs). The tandem duplication should have driven fast evolution for these prolamin genes.

Phylogenetic analysis of prolamin genes among four studied species showed that genes from the same species were tended to be clustered together. Besides, some genes were not well clustered according to species, which may due to incomplete or large changes in the protein sequences, especially HMW-GS and $\omega$-gliadin genes from common wheat, which all have a large proportion of gap regions (Additional file 1: Table S3). In addition, many of these genes have been lost or newly evolved after speciation, possibly due to unequal crossover or gene conversion (Fig. 4, Additional files 3 and 4) [40]. For instance, Th. elongatum has evolved 19 copies of $\omega$-gliadin genes, while many copies in clade 2 , clade 3 were apparently duplicated after diverging from the other species (Additional file 4). Similarly, many $\alpha$ gliadin genes in clade 1 to clade 4 are likely lost and resulting in fewer $\alpha$-gliadins in Th. elongatum genome (Fig. 4 and Fig. 6a). This fast evolution of prolamin family is accompanied with high rates of pseudogenes and large genetic diversity inner- or inter-species, and the richness of these seed-storage protein resources favor future wheat quality breeding.

According to previous reports of common wheat, the expression of LMW-GS genes began to express at the 5 th day and reached the peak at the $10 \sim 14$ th day after anthesis, and then decreased with the maturity of seeds [27]. In Th. elongatum, the expression of three LMWGS genes showed a consistent trend (Fig. 5). For the gliadin genes, their expression has genomic differences that genes from $\mathrm{B}$ and $\mathrm{D}$ subgenomes are early-expressed (highest level at 10 days after flowering), similar to the expression of LMW-GS genes, while those of the A genome are late-expressed genes (highest level at 20 days after flowering) [27]. The expression trend of $\alpha$-gliadin genes is synchronous with that of LMW-GS genes in Th. elongatum, as early-expressed genes (Fig. 5). However, the expression of $\gamma$-gliadin genes increased from the half grain to the grain stage and reached its peak later than that of $\alpha$-gliadin genes and LMW-GS genes, which demonstrated different roles of these prolamin genes in the grain development process.

Based on the putative functional $\alpha$-gliadin sequences of four species, our results showed that $C D$ peptides were genome-specific, which is consistent with the results of a previous study (Additional file 1: Table S5) [1]. Importantly, $\alpha$-gliadins of the Th. elongatum genome contain only one type $\mathrm{CD}$ peptide, which is beneficial to
low-CD breeding. Moreover, although $\alpha$-gliadin genes were both found in the sixth homologous group of CS wheat and Th. elongatum, but the CD peptide of $\alpha$ gliadins in Th. elongatum genome is much fewer than that in D genome (Additional file 1: Table S5). The grain of DS6E(6D), which replaces the chromosome 6D genome with the chromosome $6 \mathrm{E}$ genome and has been verified through cytological study (Additional file 6), were speculated for protein content by A-Page, and the protein bands for $\alpha$-gliadin genes did largely disappeared (Fig. 6a). This result indicates that the $\alpha$-gliadins locus on $\mathrm{D}$ genome can be further translocated by short $\mathrm{E}$ genome fragment by distant hybridization, generating less toxic wheat varieties for $\mathrm{CD}$ patient population. Moreover, gene silencing may also favor such utility during engineering alien chromatin into wheat background [41]. In DS6E(6D), we did found one band of $\omega$-gliadin was silenced (Fig. 6a).

\section{Conclusions}

Prolamins, the major protein component in cereal endosperm, play important roles for human diet. Here, we characterized and compared this gene family in Th. elongatum and three other wheat relatives. We explained the different expression pattern of prolamin gene subfamilies, found the dynamic changes of gene intervals, elaborated the evolutionary relationship among the Triticeae species used in this study. Our results showed that the HMW-GSs from Th. elongatum genome had highly potential for future improvement of wheat dough quality. Also, the Th. elongatum genome with low content of small $\mathrm{CD}$ peptides will be profitable genomic choice for the cultivation of wheat with low celiac disease.

\section{Methods}

\section{Identification of prolamin genes}

Genome datasets and annotation files of four species (Th. elongatum, T. aestivum, T. urartu, and Ae. tauschii) were downloaded from the Genome Warehouse (https:// bigd.big.ac.cn/gwh/Assembly/965/show), IWGSC (https://urgi.versailles.inra.fr/download/iwgsc/IWGSC_ RefSeq_Annotations/v1.1/), MBKBASE (http://mbkbase. $\operatorname{org} / \mathrm{Tu} /)$, and http:// aegilops.wheat.ucdavis.edu/ ATGSP/annotation/, respectively. Coding sequences and protein sequences of prolamin genes in $\mathrm{T}$. aestivum, $\mathrm{T}$. urartu, and Ae. tauschii were extracted from corresponding files [14-16]. The common wheat prolamin gene sequences, including HMW-GS, LMW-GS, $\alpha$-, $\delta$-, $\gamma^{-}$, and $\omega$-gliadin genes, were used as queries in blastn searches against the Th. elongatum genome sequence with an e-value cutoff of $1 \times 10^{-10}$, and then matched genes with full-length sequences (including stop codon) were extracted and manually annotated [16]. All CDSs 
and protein sequences were regenerated using the gffread program [42].

\section{Feature analysis}

Putative functional genes were deduced according to whether the amino acid sequences of prolamins could produce proteins with complete structure. The pseudogene rate of the gene family was calculated with the number of pseudogenes divided by the total number of genes. Two genes were deleted because the sequences were not completed. All putative functional prolamin sequences were submitted to Expasy (https://web.expasy. org/compute_pi/) for calculation of molecular weight (MW) and theoretical isoelectric point (pI).

\section{Distribution and duplication of prolamin genes}

The distribution of prolamin genes on chromosomes was determined by the MapChart software [43]. Three roles were used to determine whether they were tandem repeat genes [44, 45]: (a) The distance between two genes on the same chromosomal fragment was less than $100 \mathrm{~kb}$; (b) the shorter aligned sequence covered $>70 \%$ of the longer sequence; (c) the similarity of aligned sequences was $>70 \%$. If $\mathrm{AB}$ and $\mathrm{BC}$ are two pairs of tandem repeat genes (A, B, and $C$ are three adjacent genes) but $\mathrm{AC}$ does not meet the tandem replication criteria, $\mathrm{A}$ and $C$ are considered to be tandem repeat genes. The micro-synteny analysis was conducted using the JCVI software with appropriate parameters $($ cscore $=0.8)$ (https://github.com/tanghaibao/jcvi/wiki).

\section{Phylogenetic analysis and classification of each prolamin subfamily}

Phylogenetic trees were constructed using CDSs of the conservative domains derived from $\alpha$-gliadin, $\gamma$-gliadin, LMW-GS, and HMW-GS genes. The evolutionary tree of $\omega$-gliadins was constructed using gene conservative sequences. Multiple sequence alignments were first performed using the MUSCLE program with default parameters [46]. Phylogenetic trees were constructed using the MEGA X software with the maximum likelihood method [47]. Bootstrap was set as 1000 replicates. Based on model tests, the best models of these phylogenetic trees were set to be $\mathrm{TN} 93+\mathrm{G}, \mathrm{K} 2+\mathrm{G}, \mathrm{K} 2+\mathrm{I}$, and $\mathrm{T} 92+\mathrm{I}$, $\mathrm{K} 2+\mathrm{G}$ respectively [48].

\section{$\mathrm{CD}$ content detection}

The key peptides involved in the pathogenesis of $\mathrm{CD}$ are DQ2.5-glia- $\alpha 1 \mathrm{a}$ (PFPQPQLPY), DQ2.5-glia- $\alpha 1 b$ (PYPQ PQLPY), DQ2.5-glia- $\alpha 2$ (PQPQLPYPQ), DQ2.5-glia- $\alpha 3$ (FRPQQPYPQ), and a 33-mer peptide (LQLQPFPQPQ LPYPQPQLPYPQPQLPYPQPQPF). These small peptide sequences were retrieved from the deduced functional protein sequences, and the contents of these small peptides of single prolamin subfamily in the genomes of the four species were determined.

\section{Transcriptome analysis}

In order to analyze the expression patterns of prolamin genes in Th. elongatum, we sampled tissues at six stages with three biological replicates: young spike, preflowering, flowering, ovary expansion, half-grain, and grain stages. Total RNA was extracted for each sample using TRIzol ${ }^{\circ}$ Reagent (Invitrogen) according to the manufacturer's instructions. A total of 18 samples were paired-end sequenced on the Illumina HiSeq 4000 platform. The quality of all samples was checked by fastqc (v0.11.9) and controlled by fastp (v0.20.0) with default parameters $[49,50]$. Hisat2 (v2.2.1) was used to map clean reads to the genome of Th. elongatum [51]. The transcripts per kilobase of exon model per million mapped reads (TPM) value for each gene was calculated by StringTie (v2.1.2) and the heatmap was constructed by TBtools (v1.047) [52, 53].

\section{Protein extraction and gel electrophoresis The method for glutenins}

Single milled seed was suspended in $0.5 \mathrm{~mL}$ mixture extraction liquid and then incubated at $65^{\circ} \mathrm{C}$ for $2 \mathrm{~h}$. The components of the extracted liquid mixture were as follows: $25 \mathrm{~mL}$ Tris- $\mathrm{HCl}(0.5 \mathrm{M}, \mathrm{pH} 6.8), 20 \mathrm{~mL}$ glycerol, 4 g sodium dodecyl sulfate (SDS), $30 \mathrm{~g}$ bromophenol blue, and $1 \mathrm{~g}$ dithiothreitol (DTT). The total volume of above extracted liquid mixture was then made to $100 \mathrm{~mL}$ with deionized water. The glutenin subunits were separated by a discontinuous sodium dodecyl sulfate polyacrylamide gel electrophoresis (SDS-PAGE) system. The 100 $\mathrm{mL} 15 \%$ separating gel included $25 \mathrm{~mL}$ deionized water, $50 \mathrm{~mL} 30 \%$ Acryl/Bis solution (29:1), $25 \mathrm{~mL} 4 \mathrm{X}$ separation gel buffer, $1 \mathrm{~mL} 10 \%(\mathrm{~m} / \mathrm{v})$ ammonium persulfate solution and $800 \mathrm{uL}$ TEMED. The $80 \mathrm{~mL} 5 \%$ stacking gel included $45.6 \mathrm{ml}$ deionized water, $13.6 \mathrm{~mL} 30 \%$ Acryl/Bis solution (29:1), $20 \mathrm{~mL}$ concentrated rubber buffer, $800 \mathrm{uL} \mathrm{10 \%} \mathrm{(m/v)} \mathrm{ammonium} \mathrm{persulfate} \mathrm{solution}$ and $65 \mathrm{uL}$ TEMED. Gels were run at a constant current (12 mA) for $20 \mathrm{~h}$.

\section{The method for gliadins}

Single milled seed was suspended in $0.3 \mathrm{~mL} 70 \%$ ethanol and then incubated at $37^{\circ} \mathrm{C}$ for $2 \mathrm{~h}$. Acid gel composition was as follows: $0.5 \mathrm{~g}$ ascorbic acid, $0.01 \mathrm{~g} \mathrm{FeSO}_{4}, 50$ $\mathrm{g}$ acrylamide, and $2.5 \mathrm{~g}$ Bis-Tris. The total volume of each sample was then made to $500 \mathrm{~mL}$ with deionized water. The separating gel included $40 \mathrm{~mL}$ acid gel liquid, $0.3 \mathrm{~mL}$ formic acid, and $30 \mathrm{uL} 0.6 \% \mathrm{H}_{2} \mathrm{O}_{2}$. The stacking gel included $10 \mathrm{~mL}$ acid gel liquid and $0.1 \mathrm{uL} 0.6 \%$ $\mathrm{H}_{2} \mathrm{O}_{2}$. Gels were run at a constant voltage in two stages ( $150 \mathrm{~V}$ for $30 \mathrm{~min}$, then $350 \mathrm{~V}$ for $4 \mathrm{~h}$ ). 
Coomassie brilliant blue dye liquor included $1 \mathrm{~g}$ coomassie brilliant blue R-250, $100 \mathrm{~mL}$ glacial acetic acid, $250 \mathrm{~mL}$ isopropanol and $650 \mathrm{~mL}$ deionized water. The decolorizing solution included $50 \mathrm{~mL}$ anhydrous ethanol, $100 \mathrm{~mL}$ glacial acetic acid and $850 \mathrm{~mL}$ deionized water. Both gels were stained with a Coomassie brilliant blue dye liquor for $4 \mathrm{~h}$ and destained overnight.

\section{Fish}

FISH was performed with the probes oligo-psc119.2-1 from Secale cereal and oligo-pta535-1 from T. aestivum. Hybridization solution was prepared according to the number of samples prepared. The two probes were mixed at a ratio of 1:1 before hybridization. The specific methods used were performed according to previous method [54].

\section{Dough rheological properties test}

Mature grains were milled into flour using a mill for further testing. In this study, the protein and water contents of flour were determined by a DA7200 multifunction near infrared analyzer. By referring to the formula of the "AACC54-40A" method, the main mixing parameters, such as the mixing time, middle peak height, middle peak time, middle peak at $8 \mathrm{~min}$, and width at 8 min, were determined with a $10 \mathrm{~g}$ mixograph.

\section{Abbreviations \\ HMW-GS: High-molecular-weight glutenin subunit; LMW-GS: Low-molecular- weight glutenin subunit; DS: Disomic substitution; CD: Celiac disease; CS: Chinese Spring; FISH: Fluorescence in situ hybridization; bp: Base pair; kb: Kilobase; pl: Isoelectric point; MW: Molecular Weight; SDS-PAGE: Sodium dodecyl sulfate polyacrylamide gel electrophoresis; A-PAGE: Acid polyacrylamide gel electrophoresis}

\section{Supplementary Information}

The online version contains supplementary material available at https://doi. org/10.1186/s12864-021-08088-x.

Additional file 1: Table S1. Prolamin genes in Th. elongatum genome Table S2. Error correction of prolamin gene annotations in T. aestivum, Ae. tauschii and T. urartu. Table S3. Coding sequences for the prolamin genes in the four studied species. Table S4. Molecular characteristics of prolamin genes. Table S5. The distribution of CD epitopes in the genomes of T. aestivum, T. urartu, Ae. tauchii and Th. elongatum. Table S6. Transcriptome data of Th. elongatum at different development stages.

Additional file 2: Mirco-synteny analysis of each prolamin gene family between Th. elongatum and three related species. Red lines highlight the syntenic prolamin gene pairs and gray lines indicate the other syntenic gene pairs. (A) Synteny relationship of a-gliadins. (B) Synteny relationship of HMW-glutenins.

Additional file 3: Phylogenetic tree for each prolamin subfamilies. (A) Phylogenetic tree of -gliadin family. X13508.1 was set as outgroup. (B) Phylogenetic tree of LMW-GS gene family. HQ293220.1 was set as outgroup. (C) Phylogenetic tree of HMW-GS gene family. FJ481574.2 was set as outgroup.

Additional file 4: Phylogenetic tree of $\omega$-gliadin gene family. FJ600500 was set as outgroup.
Additional file 5: Expression profile of 59 starch synthesis related genes in Th. elongatum. Genes were named according to names in common wheat.

Additional file 6: The FISH pattern of DS1E(1D) and DS6E(6D). Chromosomes $1 \mathrm{E}$ and $6 \mathrm{E}$ from Th. elongatum were indicated by arrows respectively.

Additional file 7: A-PAGE patterns of gliadin in CS and its derived substitution lines.

\section{Acknowledgements}

We thank Mingzhu Li (Shandong Agricultural University) for the help with FISH experiment and Xuye Du (Guizhou Normal University) for the guidance of SDS-PAGE and A-PAGE experiments.

\section{Authors' contributions}

SLS designed and supervised this study. WYG and YG arranged, analyzed the data, performed the experiments and wrote the manuscript. SSX collected the plant materials, XM, HWW and LRK revised the manuscript. The authors read and approved the final manuscript.

\section{Funding}

This work was supported by the National Natural Science Foundation of China (31901492 and 31801352).

\section{Availability of data and materials}

The transcriptome data used in this study have been uploaded to NCBI under BioProjectID PRJNA540081 (https://www.ncbi.nlm.nih.gov/sra/PRJNA54 0081). The other data used to support the findings of this study are available from the corresponding author upon request.

\section{Declarations}

Ethics approval and consent to participate

Not applicable.

\section{Consent for publication}

Not applicable.

\section{Competing interests}

The authors declare that they have no competing interests.

Received: 10 May 2021 Accepted: 15 October 2021

Published online: 02 December 2021

\section{References}

1. van Herpen TV, Goryunova S, van der Schoot J, Mitreva M, Salentij E, Vorst $\mathrm{O}$, et al. alpha-gliadin genes from the $\mathrm{A}, \mathrm{B}$, and $\mathrm{D}$ genomes of wheat contain different sets of celiac disease epitopes. BMC Genomics. 2006;7:1.

2. Shewry PR, Halford NG, Lafiandra D. Genetics of wheat gluten proteins. Adv Genet. 2003:49:111-84.

3. Wieser H. Chemistry of gluten proteins. Food Microbiol. 2007;24:115-9.

4. Payne Pl, Holt LM, Lawrence GJ, Law CN. The genetics of gliadin and glutenin, the major storage proteins of the wheat endosperm. Plant Foods Hum Nutr. 1982;31:229-41.

5. Payne PI, Corfield KG. Subunit composition of wheat glutenin proteins, isolated by gel filtration in a dissociating medium. Planta. 1979;145:83-8.

6. Sissons MJ, Bekes F, Skerritt JH. Isolation and functionality testing of low molelght glutenin subunits. Cereal Chem. 1998;75:380-2.

7. Shewry PR, Halford NG, Belton PS, Tatham AS. The structure and properties of gluten: an elastic protein from wheat grain. Phil Trans R Soc Lond B-Biol Sci. 2002;357:133-42.

8. Anderson OD, Hsia CC, Torres $\mathrm{V}$. The wheat $\gamma$-gliadin genes: characterization of ten new sequences and further understanding of $y$-gliadin gene family structure. Theor Appl Genet. 2001:103:323-30.

9. Payne PI. Genetics of wheat storage proteins and the effect of allelic variation on bread-making quality. Ann Rev Plant Physiol. 1987;38: $141-53$.

10. Gao SC, Gu QY, Wu JJ, Devin CD, Huo NX. Rapid evolution and complex structural organization in genomic regions harboring 
multiple prolamin genes in the polyploid wheat genome. Plant Mol Biol. 2007:65:189-203.

11. Anderson OD, Litts JC, Gautier MF, Greene FC. Nucleic acid sequence and chromosome assignment of a wheat storage protein gene. Nucleic Acids Res. 1984;12:8129-44.

12. Petersen G, Seberg O, Yde M, Berthelsen K. Phylogenetic relationships of Triticum and Aegilops and evidence for the origin of the $a, B$, and D genomes of common wheat (Triticum aestivum). Mol Phylogenet Evol. 2006;39:70-82

13. Wang H, Sun S, Ge W, Zhao L, Hou B, Wang K, et al. Horizontal gene transfer of Fhb7 from fungus underlies Fusarium head blight resistance in wheat. Science. 2020;368:eaba5435.

14. The International Wheat Genome Sequencing Consortium (IWGSC), Rudi A, Kellye E, Nils S, Beat $K$, Jane R, et al. Shifting the limits in wheat research and breeding using a fully annotated reference genome. Science. 2018;361: 661.

15. Luo MC, Gu YQ, Puiu D, Wang H, Twardziok SO, Deal KR, et al. Genome sequence of the progenitor of the wheat $\mathrm{D}$ genome Aegilops tauschii. Nature. 2017;551:498-502.

16. Ling HQ, Ma B, Shi X, Liu H, Dong L, Sun H, et al. Genome sequence of the progenitor of wheat a subgenome Triticum urartu. Nature. 2018;557:424-8.

17. Gorwa MF, Croux C, Soucaille P. Molecular characterization and transcriptional analysis of the putative hydrogenase gene of clostridium acetobutylicum ATCC 824. J Bacteriol. 1996;178:2668.

18. Huo N, Zhu T, Altenbach S, Dong L, Wang Y, Mohr T, et al. Dynamic evolution of alpha-gliadin prolamin gene family in homeologous genomes of hexaploid wheat. Sci Rep. 2018;8:5181.

19. Bennetzen JL. Comparative sequence analysis of plant nuclear genomes. Microcolinearity and its many exceptions. Plant Cell. 2000; 12:1021-9.

20. Kong XY, Gu YQ, You FM, Dubcovsky J, Anderson OD. Dynamics of the evolution of orthologous and paralogous portions of a complex locus region in two genomes of allopolyploid wheat. Plant Mol Biol. 2004;54:5569.

21. Stamnaes J, Sollid LM. Celiac disease. Autoimmunity in response to food antigen. Semin Immunol. 2015;27:343-52.

22. Sharma N, Ch V, Sharma S, Kapoor P, Garg M. Pathogenesis of celiac disease and other gluten related disorders in wheat and strategies for mitigating them. Front Nutr. 2020. https://doi.org/10.3389/fnut.2 020.00006 .

23. Shewry PR, Tatham AS. Improving wheat to remove coeliac epitopes but retain functionality. J Cereal Sci. 2016;67:12-21.

24. Wang S, Shen X, Ge P, Li J, Subburaj S, Li X, et al. Molecular characterization and dynamic expression patterns of two types of $\gamma^{-}$ gliadin genes from Aegilops and Triticum species. Theor Appl Genet. 2012;125:1371-84.

25. Tatham AS, Shewry PR. The S-poor prolamins of wheat, barley and rye: revisited. J Cereal Sci. 2012;55:79-99.

26. Anderson OD, Litts JC, Greene FC. The a-gliadin gene family. I. Characterization of ten new wheat a-gliadin genomic clones, evidence for limited sequence conservation of flanking DNA, and southern analysis of the gene family. Theor Appl Genet. 1997;95:50-8.

27. Liu CY, Shepherd KW. Inheritance of B subunits of glutenin and omegaand gamma-gliadins in tetraploid wheats. Theor Appl Genet. 1995;90: 1149-57.

28. Masci S, D'Ovidio R, Lafiandra D, Kasarda DD. A 1B-coded low-molecularweight glutenin subunit associated with quality in durum wheats shows strong similarity to a subunit present in some bread wheat cultivars. Theor Appl Genet. 2000;100:396-400.

29. Jackson EA, Holt LM, Payne PI. Characterisation of high molecular weight gliadin and low-molecular-weight glutenin subunits of wheat endosperm by two-dimensional electrophoresis and the chromosomal localisation of their controlling genes. Theor Appl Genet. 1983;66:29-37.

30. Payne PI, Holt LM, Worland AJ, Law CN. Structural and genetical studies on the high-molecular-weight subunits of wheat glutenin: part 3. Telocentric mapping of the subunit genes on the long arms of the homoeologous group 1 chromosomes. Theor Appl Genet. 1982;63:129-38.

31. Gu YQ, Coleman DD, Kong X, Anderson OD. Rapid genome evolution revealed by comparative sequence analysis of orthologous regions from four triticeae genomes. Plant Physiol. 2004;135:459-70

32. Kasarda DD, Ovidio RD. Deduced amino acid sequence of an a-gliadin gene from spelt wheat (Spelta) includes sequences active in celiac disease. Cereal Chem. 1999;76:548-51.

33. Stern M, Ciclitira PJ, van Eckert R, Feighery C, Janssen FW, Mendez E, et al. Analysis and clinical effects of gluten in coeliac disease. Eur J Gastroenterol Hepatol. 2001;13:741-7.

34. Gu Y, Han S, Chen L, Mu J, Duan L, Yan Y, et al. Expression and regulation of genes involved in the reserve starch biosynthesis pathway in hexaploid wheat (Triticum aestivum L.). Crop J. 2021:9:440-55.

35. Ohdan T, Francisco PB Jr, Sawada T, Hirose T, Terao T, Satoh H, et al. Expression profiling of genes involved in starch synthesis in sink and source organs of rice. J Exp Bot. 2005;56:3229-44.

36. Wang Z, Li W, Qi J, Shi P, Yin Y. Starch accumulation, activities of key enzyme and gene expression in starch synthesis of wheat endosperm with different starch contents. J Food Sci Technol. 2014; 51(3):419-29

37. Gaál E, Valárik M, Molnár I, Farkas A, Linc G. Identification of COS markers specific for Thinopyrum elongatum chromosomes preliminary revealed high level of macrosyntenic relationship between the wheat and Th. elongatum genomes. PLoS One. 2018;13:e0208840.

38. Rey E, Abrouk M, Keeble-Gagnère $G$, et al. Transcriptome reprogramming due to the introduction of a barley telosome into bread wheat affects more barley genes than wheat. Plant Biotechnol J. 2018;16(10):1767-77. https:// doi.org/10.1111/pbi.12913.

39. Anderson OD, Huo N, Gu YQ. The gene space in wheat: the complete $\gamma^{-}$ gliadin gene family from the wheat cultivar Chinese spring. Funct Integr Genomics. 2013;13:261-73.

40. Smith GP. Evolution of repeated DNA sequences by unequal crossover. Science. 1976;191:528-35.

41. Fan $X$, Zhang HQ, Sha LN, Zhang L, Yang RW, Ding CB, et al. Phylogenetic analysis among Hystrix, Leymus and its affinitive genera (Poaceae: Triticeae) based on the sequences of a gene encoding plastid acetyl-CoA carboxylase. Plant Sci. 2007;172:701-7.

42. Pertea G, Pertea M. GFF Utilities: GffRead and GffCompare. F1000Res. 2020;9:304.

43. Gu Z, Cavalcanti A, Chen FC, Bouman P, Li WH. Extent of gene duplication in the genomes of drosophila, nematode, and yeast. Mol Biol Evol. 2002;3: 256-62.

44. Yang SH, Zhang XH, Yue JX, Tian DC, Chen JC. Recent duplications dominate NBS-encoding gene expansion in two woody species. Mol Gen Genomics. 2008:280:187-98.

45. Sun $\mathrm{H}$, Fan $\mathrm{HJ}$, Ling $\mathrm{HQ}$. Genome-wide identification and characterization of the bHLH gene family in tomato. BMC Genomics. 2015;16:9.

46. Lozano R, Hamblin MT, Prochnik S, Jannink JL. Identification and distribution of the NBS-LRR gene family in the cassava genome. BMC Genomics. 2015:16:360.

47. Sudhir K, Glen S, Michael L, Christina K, Koichiro T. MEGA X: Molecular evolutionary genetics analysis across computing platforms. Mol Biol Evol. 2018:35:1547-9.

48. Thomas RH. Molecular evolution and Phylogenetics. Heredity. 2000; $86: 385$

49. Chen S, Zhou Y, Chen Y, Jia G. fastp: an ultra-fast all-in-one FASTQ preprocessor. Bioinformatics. 2018;34:1884-90.

50. Wingett SW, Andrews S. FastQ screen: a tool for multi-genome mapping and quality control. F1000 Res. 2018;7:1338

51. Kim D, Langmead B, Salzberg SL. HISAT: a fast spliced aligner with low memory requirements. Nat Methods. 2015;12:357-60.

52. Kovaka S, Zimin AV, Pertea GM, Razaghi R, Pertea M. Transcriptome assembly from long-read RNA-seq alignments with StringTie2. Genome Biol. 2019. https://doi.org/10.1186/s13059-019-1910-1.

53. Chen CJ, Chen H, Zhang Y, Thomas HR, Frank MH, He Y, et al. TBtools: an integrative toolkit developed for interactive analyses of big biological data. Mol Plant. 2020;13:1194-202

54. Han F, Liu B, Fedak G, Liu Z. Genomic constitution and variation in five partial amphiploids of wheat-Thinopyrum intermedium as revealed by GISH, multicolor GISH and seed storage protein analysis. Theor Appl Genet. 2004;109:1070-6.

\section{Publisher's Note}

Springer Nature remains neutral with regard to jurisdictional claims in published maps and institutional affiliations. 